\title{
Melissa officinalis: a memory enhancer remedy
}

\author{
Mehdi Eivani $^{1 *}$ iD, Nahid Khosronezhad ${ }^{2}$ \\ 1. Neuroscience Lab, Department of Animal Biology, School of Biology, College of Science, University of Tehran, Tehran, Iran \\ 2. Department of Cell and Molecular Biology, School of Biology, College of Science, University of Tehran, Tehran, Iran
}

\begin{abstract}
Melissa officinalis (MO) is a perennial herb and it is a member of Lamiaceae family. $\mathrm{MO}$ is native to Europe and the leaves of the plants are used in traditional medicine for its effects on the central nervous system functions such as sedation, anxiolytic and memory enhancement. Furthermore, MO has antioxidant and anti-inflammatory effects. Convincing evidence shows that molecular changes such as oxidative stress and inflammation are associated with a decline in cognitive abilities, including learning and memory. $\mathrm{MO}$ and its main ingredient, rosmarinic acid, possess robust antioxidant and anti-inflammatory effects. Besides, animal model studies have shown that $\mathrm{MO}$ and rosmarinic acid can improve memory loss in Alzheimer's disease. In this review beneficial implications of $\mathrm{MO}$ have been discussed.
\end{abstract}

http://dx.doi.org/10.32598/ppj.24.3.10

\section{Keywords:}

Melissa officinalis;

Memory impairment;

Alzheimer's disease;

Antioxidant;

Anti-inflammatory

* Corresponding author:

M. Eivani

Email: m.eivani@ut.ac.ir

Tel: +98 (912) 0121986

Received 14 April 2020;

Received in revised form 14

May 2020; Accepted 26 May

2020

\section{Introduction}

Melissa officinalis L. (MO), also known as lemon balm, is used in traditional medicine for its effects on central nervous system (CNS) functions (Shakeri et al., 2016) such as sedation (Ghazizadeh et al., 2020) and memory-enhancement (Dehbani et al., 2019). There is a growing body of research that indicates beneficial implications of $\mathrm{MO}$ in treatment of diseases including diabetes (Khodsooz et al., 2016) and Alzheimer's disease (AD) (Akhondzadeh et al., 2003). Furthermore, $\mathrm{MO}$ has antioxidant (Alizadeh Behbahani et al., 2019), antimicrobial (Hassan et al., 2019) and anti-inflammatory (Bounihi et al., 2013) effects. Rosmarinic acid as the main active substance in $\mathrm{MO}$ is an ester of caffeic acid and 3, 4dihydroxiphenyllactic acid (Petersen and Simmonds, 2003). Learning and memory are the supreme functions of CNS (Kandel, 2001). Memory has been divided into two distinct stages: short-term memory and long-term memory, which its formation requires de novo transcription and protein synthesis (Eivani et al., 2019). In this review, we discuss the potential effect of $\mathrm{MO}$ on memory formation and memory impairment.

\section{Melissa officinalis and memory}

There is a growing tendency for memory-enhancing medicinal herbs (Jivad and Rabiei, 2014). MO is one of the medicinal herbs frequently used for memory enhancement. In an animal study, chronic (14 days) oral administration of $\mathrm{MO}$ hydro-alcoholic extract (50, 100 and $200 \mathrm{mg} / \mathrm{kg}$ ) was shown to augment the learning and memory in the passive avoidance task in adult rats (Dehbani et al., 2019). MO also, can improve memory function in healthy individuals, the 
Table 1: Memory enhancement effect of MO and rosmarinic acid in animal models of Alzheimer's disease

\begin{tabular}{lcccc}
\hline Treatment & $\begin{array}{c}\text { Route of } \\
\text { administration }\end{array}$ & Model & Test & Reference \\
\hline RA & IP & ICV injection of A & $\begin{array}{c}\text { Y-maze test } \\
\text { Novel object } \\
\text { recognition task }\end{array}$ & Alkam et al., 2007 \\
\hline RA & IP & intrahippocampal & Y-maze test & Baluchnejadmojarad et al., 2013 \\
injection of A $\beta$ & passive avoidance test & \\
\hline RAMO & PO & ICV injection of A & passive avoidance test & Beheshti and Shahmoradi, 2018 \\
\hline HAMO & PO & IP injection of & passive avoidance test & Hasanein and Mahtaj, 2015 \\
\hline HAMO & IP & IP injection of & Morris water maze & Soodi et al., 2013 \\
\hline
\end{tabular}

RA: rosmarinic acid, HAMO: hydro-alcoholic extract of Melissa officinalis, PO: gavage, IP: intraperitoneal injection, ICV: intracerebroventricular injection

results of a randomized, placebo-controlled, doubleblind, balanced-crossover study conducted by Kennedy and colleagues in 2002 suggest that oral administration of a single dose of $\mathrm{MO}$ can modulate memory performance of healthy young volunteers in cognitive drug research computerized assessment test.

\section{Melissa officinalis and memory impairment}

Alcohol consumption affects the CNS, causing neuronal damage and a wide range of cognitive declines such as memory impairment (White et al., 2000). Research on laboratory animals has shown that chronic administration of rosmarinic acid prevents ethanol-induced amnesia in a dose dependent manner (Hasanein and Mahtaj, 2015).

Stroke is the fourth leading cause of death worldwide and the major cause of disability, ischemic injury is associated with inflammation and free radical metabolites (Kriz, 2006). It has been demonstrated that stroke can result in memory impairment (Kim et al., 2020) and the prevalence of post-stroke cognitive decline ranges from 20 to 80 percent (Sun et al., 2014). In a study carried out by Fonteles and colleagues in 2016, the effect of rosmarinic acid against memory deficits in ischemic mice was investigated. Their results revealed that rosmarinic acid inhibits the inflammatory response and prevents memory impairment induced by cerebral ischemia.

People worldwide are living longer, the proportion of older people has been increasing over the last century. A complication associated with age is memory decline (Koen et al., 2019). In a randomized, parallel, double-blind, placebo-controlled clinical trial carried out by Taghizadeh et al. (2018) results indicated that MO could be beneficial for age-related memory impairments. They found that the chronic (one month) consumption of $\mathrm{MO}$ in combination with Boswellia serrata (a plant that produces frankincense) in participants led to a significant increase in memory compared to placebo.

\section{Melissa officinalis and Alzheimer's disease}

One of the most common type of dementia is $A D$. Approximately $70 \%$ of all dementia cases are recognized as $A D$. The most common risk factors for developing $A D$ are age, genetic, vascular diseases and environmental factors. Prevalent and distinctive indications present within the patient's brain are the senile plaques and neurofibrillary tangles that are the result of the aggregation of two key molecules, tau and amyloid- $\beta$ (A $\beta$ ) (Castellani et al., 2010). Animal models of $A D$ comprise a group of inducible models with certain aspects of AD (Götz et al., 2018) such as intracranial injection of synthetic $A \beta$ (Beheshti and Shahmoradi, 2018), intracranial and intraperitoneal injection of scopolamine (Aykac et al., 2019) and intracranial injection of streptozotocin (Rostami et al., 2017; Grieb, 2016). Moreover, MO has been traditionally used for the treatment of dementia and $A D$, with the most characteristic manifestation of all dementia cases is the impairment of learning and memory. Animal model studies show that the hydroalcoholic extract of MO can improve memory loss in 


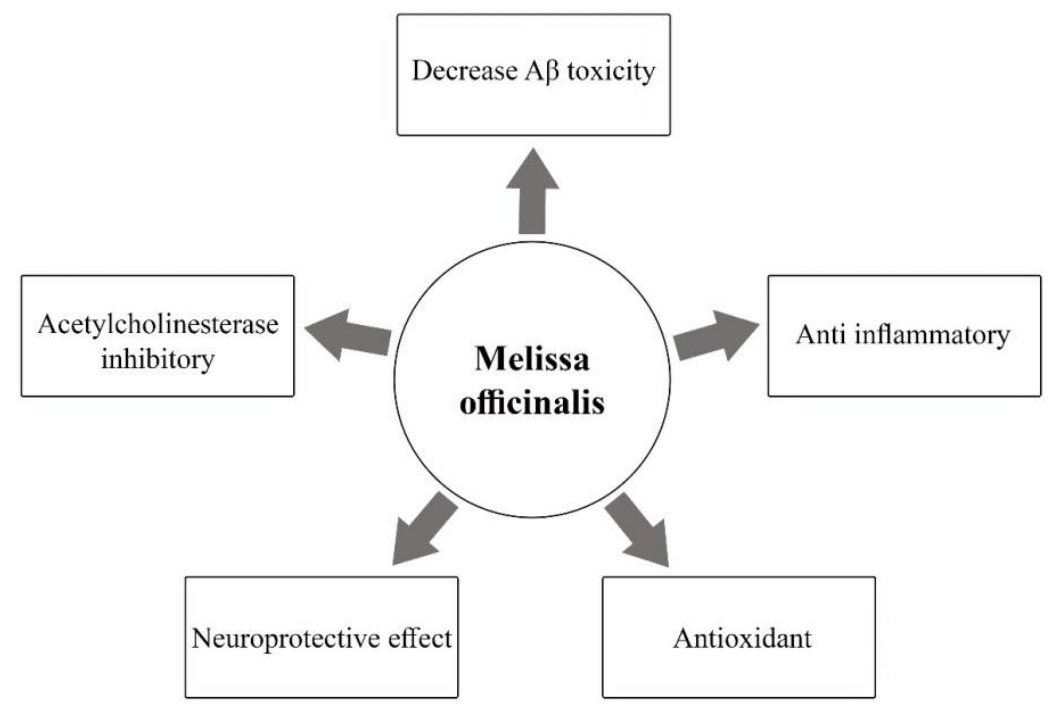

Fig.1. Possible mechanism of action of Melissa officinalis in memory enhancement.

AD (Table 1) (Beheshti and Shahmoradi, 2018; Sabbaghziarani et al., 2014; Soodi et al., 2014). Studies performed on rosmarinic acid as the main gradient of $\mathrm{MO}$, also demonstrate memory enhancement effects in animal models of $A D$ (Table 1) (Alkam et al., 2007; Baluchnejadmojarad et al., 2013; Hasanein and Mahtaj, 2015).

Evidence shows that molecular changes such as oxidative stress, precede the onset of clinical dementia (Wojsiat et al., 2018). Both the hydroalcoholic extract of MO (Koksal et al., 2011) and rosmarinic acid (Adomako-Bonsu et al., 2017) possess robust antioxidant properties. From another point of view, $\beta$-secretase is a key enzyme in the amyloidogenic pathway and its activity leads to the accumulation of neurotoxic forms of $A \beta$ ( $\mathrm{Hu}$ et al., 2010; Venugopal et al., 2008). It was found that glycogen synthase kinase-3 $\beta$ (GSK-3 $\beta$ ) has been actively involved with $A \beta$ toxicity and tau pathologies (Takashima, 2006) and that methanolic extract of MO has inhibitory effects on GSK-3 $\beta$ and $\beta$-secretase (Gürbüz et al., 2019)

\section{Acetylcholinesterase inhibitory effect of Melissa officinalis}

One of the pathological factors of $A D$ is the reduction of acetylcholine (Ach) neurotransmission in the brain areas dealing with learning and memory (Quirion, 1993). Acetylcholinesterase (AChE) is primarily responsible for the hydrolysis of ACh and its synaptic clearance (Soreq and Seidman, 2001). Therefore, $A C h E$ inhibitors such as rivastigmine can alleviate $A D$ symptoms by increasing the level of acetylcholine in the synapses and there are several candidate drugs for the clinical management of AD (Anand et al., 2012). On the contrary, anticholinergic drugs, such as scopolamine, can mimic learning and memory impairments associated with $A D$ (Potasiewicz et al., 2020).

In a study carried out by Dastmalchi et al. (2009), the MO extract demonstrated acetylcholinesterase inhibitory activites. Based on their results, the fraction containing rosmarinic acid had the most potent AChE inhibitory effect (Dastmalchi et al., 2009). Another study also confirmed AChE inhibitory effect of rosmarinic acid (Gülçin et al, 2016). Furthermore, AChE inhibitory activity was exhibited by the essential oils from MO (Chaiyana and Okonogi, 2012).

\section{Anti-inflammatory effect of Melissa officinalis and memory}

Neurodegenerative diseases, including $A D$, Parkinson's disease and amyotrophic lateral sclerosis (ALS) are often associated with neuroinflammation (Jung et al., 2019; Kitazawa et al, 2005). Synthesis and the release of chemical mediators such as cytokines and chemokines in glial cells, play an important role in neuroinflammation (Kielian, 2004). In animal experiments, lipopolysaccharide (LPS), gramnegative bacteria endotoxin, is used to induce inflammatory responses (Zhao et al., 2019). Intraperitoneal injection of LPS has been shown to induce memory impairments in rodents (Beheshti and Karimi, 2016). Investigation in animal models has 
shown that the aqueous extract of $\mathrm{MO}$ can inhibit histamine-induced and carrageenan-induced inflammation (Birdane et al., 2007). Additionally, MO essential oil has anti-inflammatory properties (Bounihi et al., 2013). Herbs with anti-inflammatory effects such as MO, might be a potential strategy in the management of inflammatory-induced memory impairments.

\section{Antioxidant effect of Melissa officinalis and memory}

During oxygen metabolism in the living organisms, reactive oxygen species (ROS) are produced (Liguori et al., 2018). Oxidative stress is imbalanced between ROS and antioxidant defenses, and evidence show that oxidative stress is associated with pathogenesis and progression of $A D$ (Butterfield and Halliwell, 2019) and memory impairments (Alzoubi et al., 2012). It is well established that $M O$ has robust antioxidant activity (Ghazizadeh et al, 2020; Miraj et al., 2017). Moreover, it is shown that the antioxidant activity of $\mathrm{MO}$ aqueous extract is related to reducing lipid peroxidation and increasing superoxide dismutase and catalase activities (Martins et al., 2012). Antioxidant properties of MO can be beneficial for the management of oxidative stress associated with memory decline.

\section{Toxicological evaluation of Melissa officinalis}

The use of traditional and herbal medicines has been increased in the last few years; however, the safety of medicinal plants requires more attention. In other terms, details on the toxicity of the plants are crucial before the development of new herbal medicines. Toxicity of hydro-alcoholic extract of $\mathrm{MO}$ was evaluated in an experiment carried out by Hashemnia et al. (2017). Their results showed that chronic (600 and $1200 \mathrm{mg} / \mathrm{kg}$ for 30 days) oral administration of hydro-alcoholic extract of $\mathrm{MO}$ induces hepatic and renal lesions in animals.

\section{Conclusion}

MO is a valuable herb that is widely used for therapeutic and non-therapeutic purposes. As mentioned earlier, MO possesses several favorable effects like anti-inflammation, anti-oxidant, AChE inhibition and prevention of beta-amyloid accumulation, and these effects make $\mathrm{MO}$ a potential medication for memory enhancement. However, further studies are required to investigate the safety of long-term consumption of $\mathrm{MO}$. It would be an interesting topic to investigate the AChE inhibitory effect of $\mathrm{MO}$ on nicotine addiction treatment.

\section{Acknowledgments}

The authors would like to thank Dr. Shaghayegh Navabpour for her helpful advice.

\section{Conflict of interest}

The authors declared no competing interests.

\section{References}

Adomako-Bonsu AG, Chan SL, Pratten M, Fry JR. Antioxidant activity of rosmarinic acid and its principal metabolites in chemical and cellular systems: Importance of physico-chemical characteristics. Toxicol In Vitro 2017; 40: 248-55. https://doi.org/10.1016/j.tiv. 2017.01.016

Akhondzadeh S, Noroozian M, Mohammadi M, Ohadinia S, Jamshidi $A H$, Khani $M$. Melissa officinalis extract in the treatment of patients with mild to moderate Alzheimer's disease: a double blind, randomised, placebo controlled trial. J Neurol Neurosur Ps 2003; 74: 863-6. https://doi.org/10.1136/jnnp.74.7.863

Alizadeh Behbahani B, Shahidi F. Melissa officinalis essential oil: chemical compositions, antioxidant potential, total phenolic content and antimicrobial activity. Nutr Food Sci Res 2019; 6: 17-25. https://doi.org/10.29252/nfsr.6.1.17

Alkam T, Nitta A, Mizoguchi $H$, Itoh A, Nabeshima T. A natural scavenger of peroxynitrites, rosmarinic acid, protects against impairment of memory induced by Aß25-35. Behav Brain Res 2007; 180: 139-45. https://doi.org/10.1016/j.bbr.2007.03.001

Alzoubi KH, Khabour OF, Rashid BA, Damaj IM, Salah HA. The neuroprotective effect of vitamin $E$ on chronic sleep deprivation-induced memory impairment: the role of oxidative stress. Behav Brain Res 2012; 226: 205-10. https://doi.org/10.1016/j.bbr.2011.09.017

Anand $\mathrm{P}$, Singh B, Singh N. A review on coumarins as acetylcholinesterase inhibitors for Alzheimer's disease. Bioorg Med Chem 2012; 20: 1175-80. https://doi.org/10. 1016/j.bmc.2011.12.042

Aykac A, Ozbeyli D, Uncu M, Ertaş B, Kılınc O, Şen A, et al. Evaluation of the protective effect of Myrtus communis in scopolamine-induced Alzheimer model through cholinergic receptors. Gene. 2019;689:194-201.

Baluchnejadmojarad T, Roghani M, Kazemloo P. Rosmarinic acid mitigates learning and memory disturbances in amyloid $\beta$ (25-35)-induced model of Alzheimer's disease in rat. $\mathrm{J}$ Basic Clin Pathophysio 2013; 2: 7-14

Beheshti S, Karimi B. Frankincense improves memory retrieval in rats treated with lipopolysaccharide. J HerbMed Pharmacol. 2016;5. 
Beheshti S, Shahmoradi B. Therapeutic effect of Melissa officinalis in an amyloid- $\beta$ rat model of alzheimer's disease. J Herbmed Pharmacol 2018; 7. https://doi.org/ 10.15171/jhp.2018.31

Birdane YO, Buyukokuroglu ME, Birdane FM, Cemek M, Yavuz $\mathrm{H}$. Anti-inflammatory and antinociceptive effects of Melissa officinalis L. in rodents. Rev Med Vet 2007; 158: 75-81.

Bounihi A, Hajjaj G, Alnamer R, Cherrah Y, Zellou A. In vivo potential anti-inflammatory activity of Melissa officinalis L. essential oil. Adv Pharmacol Sci 2013; 2013. https://doi.org/10.1155/2013/101759

Butterfield DA, Halliwell B. Oxidative stress, dysfunctional glucose metabolism and Alzheimer disease. Nat Rev Neurosci 2019; 20: 148-60. https://doi.org/10.1038/ s41583-019-0132-6

Castellani RJ, Rolston RK, Smith MA. Alzheimer disease. Dis Mon; 2010; 56: 484. https://doi.org/10.1016/j. disamonth.2010.06.001

Chaiyana W, Okonogi S. Inhibition of cholinesterase by essential oil from food plant. Phytomedicine 2012; 19: 836-9. https://doi.org/10.1016/j.phymed.2012.03.010

Dastmalchi K, Ollilainen V, Lackman P, af Gennäs GB, Dorman HD, Järvinen PP, et al. Acetylcholinesterase inhibitory guided fractionation of Melissa officinalis $\mathrm{L}$. Bioorg Med Chem 2009; 17: 867-71. https://doi.org/ 10.1016/j.bmc.2008.11.034

Dehbani Z, Komaki A, Etaee F, Shahidi S, Taheri M, Komaki S, et al. Effect of a hydro-alcoholic extract of Melissa officinalis on passive avoidance learning and memory. J Herbmed Pharmacol 2019; 8: 120-5. https://doi.org/10.15171/jhp.2019.19

Eivani M, Alijanpour S, Arefian E, Rezayof A. Corticolimbic analysis of microRNAs and protein expressions in scopolamine-induced memory loss under stress. Neurobiol Learn Mem 2019; 164: 107065. https://doi.org/10.1016/j.nlm.2019.107065

Farzan B, Abbaszadeh S, Basati G, Teimouri H. An overview of the most important medicinal plants effective on the strength of memory and mind in Iranian ethnobotany. J Pharm Pharmacogn Res 2019; 7: 15662.

Fonteles AA, de Souza CM, de Sousa Neves JC, Menezes APF, do Carmo MRS, Fernandes FDP, et al. Rosmarinic acid prevents against memory deficits in ischemic mice. Behavioural Brain Research SreeTestContent1. 2016;297:91-103.

Ghazizadeh J, Hamedeyazdan S, Torbati M, Farajdokht F, Fakhari A, Mahmoudi J, et al. Melissa officinalis $L$. hydro-alcoholic extract inhibits anxiety and depression through prevention of central oxidative stress and apoptosis. Exp Physiol 2020; 105: 707-20. https://doi.org/10.1113/EP088254

Götz J, Bodea LG, Goedert M. Rodent models for Alzheimer disease. Nat Rev Neurosci 2018; 19: 583-98. https://doi.org/10.1038/s41583-018-0054-8

Grieb P. Intracerebroventricular streptozotocin injections as a model of Alzheimer's disease: in search of a relevant mechanism. Mol Neurobiol 2016; 53: 1741-52. https://doi.org/10.1007/s12035-015-9132-3

Gülçin İ, Scozzafava A, Supuran CT, Koksal Z, Turkan F, Çetinkaya S, et al. Rosmarinic acid inhibits some metabolic enzymes including glutathione S-transferase, lactoperoxidase, acetylcholinesterase, butyrylcholinesterase and carbonic anhydrase isoenzymes. J Enzym Inhib Med Ch 2016; 31: 1698702. https://doi.org/10.3109/14756366.2015.1135914

Gürbüz P, Martinez A, Pérez C, Martínez-González L, Göger F, Ayran I. Potential anti-Alzheimer effects of selected Lamiaceae plants through polypharmacology on glycogen synthase kinase-3 $\beta$, $\beta$-secretase, and casein kinase 1ס. Ind Crops Prod 2019; 138: 111431. https://doi.org/10.1016/j.indcrop.2019.05.080

Hasanein P, Mahtaj AK. Ameliorative effect of rosmarinic acid on scopolamine-induced memory impairment in rats. Neurosci lett 2015; 585: 23-7. https://doi.org/ 10.1016/j.neulet.2014.11.027

Hashemnia M, Rezaei F, Nikousefat Z, Bahiraei M. Toxicological evaluation of chronic oral administration of Melissa officinalis hydro-ethanol extract in SpragueDawley rats. Vet Sci Dev 2017; 7. https://doi.org/ 10.4081/vsd.2017.6298

Hassan RA, Abotaleb ST, Hamed HB, Eldeen MS. Antioxidant and antimicrobial activities of Melissa officinalis L.(lemon balm) extracts. J Agric Food Chem 2019; 10: 183-7. https://doi.org/10.21608/jacb.2019. 56823

Hu X, Zhou X, He W, Yang J, Xiong W, Wong P, et al. BACE1 deficiency causes altered neuronal activity and neurodegeneration. J Neurosci 2010; 30: 8819-29. https://doi.org/10.1523/JNEUROSCI.1334-10.2010

Jivad N, Rabiei Z. A review study on medicinal plants used in the treatment of learning and memory impairments. Asian Pac J Trop Biomed 2014; 4: 780-9. https://doi.org/10.12980/APJTB.4.2014APJTB-20140412

Jung YJ, Tweedie D, Scerba MT, Greig NH. Neuroinflammation as a factor of neurodegenerative disease: thalidomide analogs as treatments. Front Cell Dev Biol 2019; 7: 313. https://doi.org/10.3389/fcell. 2019.00313

Kandel ER. The molecular biology of memory storage: a dialogue between genes and synapses. Science 2001; 294: 1030-8. https://doi.org/10.1126/science.1067020

Kennedy DO, Scholey AB, Tildesley NT, Perry EK, Wesnes KA. Modulation of mood and cognitive performance following acute administration of Melissa officinalis (lemon balm). Pharmacol Biochem Behav 2002; 72: 953-64. https://doi.org/10.1016/S0091-3057(02)00777-3

Khodsooz S, Moshtaghian J, Eivani M. Antihyperglycemic and antihyperlipidemic effects of hydroalcoholic extract of Melissa officinalis (lemon balm) in alloxan-induced diabetic rats. Physiol Pharmacol 2016; 20: 24-30.

Kielian T. Microglia and chemokines in infectious diseases of the nervous system: views and reviews. Front Biosci 2004; 9: 50. https://doi.org/10.2741/1266

Kim H, Seo JS, Lee SY, Ha KT, Choi BT, Shin YI, et al. AIM2 inflammasome contributes to brain injury and 
chronic post-stroke cognitive impairment in mice. Brain Behav Immu 2020. https://doi.org/10.1016/j.bbi.2020. 03.011

Kitazawa M, Oddo S, Yamasaki TR, Green KN, LaFerla FM. Lipopolysaccharide-induced inflammation exacerbates tau pathology by a cyclin-dependent kinase 5-mediated pathway in a transgenic model of Alzheimer's disease. J Neurosci 2005; 25: 8843-53. https://doi.org/10.1523/JNEUROSCI.2868-05.2005

Koen JD, Hauck N, Rugg MD. The relationship between age, neural differentiation, and memory performance. $J$ Neurosci 2019; 39: 149-62. https://doi.org/10.1523/J NEUROSCI.1498-18.2018

Koksal E, Bursal E, Dikici E, Tozoglu F, Gulcin I. Antioxidant activity of Melissa officinalis leaves. J Med Plant Res 2011; 5: 217-22.

Kriz J. Inflammation in ischemic brain injury: timing is important. Crit Rev Neurobio 2006; 18. https://doi.org/ 10.1615/CritRevNeurobiol.v18.i1-2.150

Liguori I, Russo G, Curcio F, Bulli G, Aran L, Della-Morte D, et al. Oxidative stress, aging, and diseases. Clin interv aging 2018; 13: 757. https://doi.org/10.2147/CIA. S158513

Martins EN, Pessano NT, Leal L, Roos DH, Folmer V, Puntel GO, et al. Protective effect of Melissa officinalis aqueous extract against $\mathrm{Mn}$-induced oxidative stress in chronically exposed mice. Brain Res Bull 2012; 87: 749. https://doi.org/10.1016/j.brainresbull.2011.10.003

Miraj S, Rafieian-Kopaei, Kiani S. Melissa officinalis L: a review study with an antioxidant prospective. Evid Based Complementary Altern 2017; 22: 385-94. https://doi.org/10.1177/2156587216663433

Petersen M, Simmonds MS. Rosmarinic acid. Phytochemistry 2003; 62: 121-5. https://doi.org/ 10.1016/S0031-9422(02)00513-7

Potasiewicz A, Krawczyk M, Gzielo K, Popik P, Nikiforuk A. Positive allosteric modulators of alpha 7 nicotinic acetylcholine receptors enhance procognitive effects of conventional anti-Alzheimer drugs in scopolaminetreated rats. Behav Brain Res 2020; 385: 112547. https://doi.org/10.1016/j.bbr.2020.112547

Quirion R. Cholinergic markers in Alzheimer disease and the autoregulation of acetylcholine release. J Psychiatry Neurosci 1993; 18: 226.

Rostami F, Javan M, Moghimi A, Haddad-Mashadrizeh A, Fereidoni M. Streptozotocin-induced hippocampal astrogliosis and insulin signaling malfunction as experimental scales for subclinical sporadic Alzheimer model. Life Sci 2017; 188: 172-85. https://doi.org/ 10.1016/j.Ifs.2017.08.025

Sabbaghziarani F, Rasapour S, Mortezaee K, Oryan S, Sharifzadeh M, Khanavi M, et al. Could Melissa officinalis extract restore streptozotocin-induced spatial memory impairment in rats? Anat Sci J 2014; 11: 25-32.

Shakeri A, Sahebkar A, Javadi B. Melissa officinalis L.-a review of its traditional uses, phytochemistry and pharmacology. J Ethnopharmacol 2016; 188: 204-28. https://doi.org/10.1016/j.jep.2016.05.010

Soodi M, Naghdi N, Hajimehdipoor H, Choopani S, Sahraei E. Memory-improving activity of Melissa officinalis extract in naïve and scopolamine-treated rats. Res pharm sci 2014; 9: 107.

Soreq H, Seidman S. Acetylcholinesterase-new roles for an old actor. Nat Rev Neurosci 2001; 2: 294-302. https://doi.org/10.1038/35067589

Sun JH, Tan L, Yu JT. Post-stroke cognitive impairment: epidemiology, mechanisms and management. Ann Transl Med 2014; 2.

Taghizadeh M, Maghaminejad F, Aghajani M, Rahmani M. The effect of tablet containing Boswellia serrata and Melisa officinalis extract on older adults' memory: a randomized controlled trial. Arch Gerontol Geriat 2018; 75: 146-50. https://doi.org/10.1016/j.archger.2017.12. 008

Takashima A. GSK-3 is essential in the pathogenesis of Alzheimer's disease. J Alzheimers Dis 2006; 9: 309-17. https://doi.org/10.3233/JAD-2006-9S335

Venugopal C, Demos CM, Jagannatha Rao KS, Pappolla MA, Sambamurti K. Beta-secretase: structure, function, and evolution. CNS Neurol Disord Drug Targets 2008; 7: 278-94. https://doi.org/10.2174/1871527087849366 26

White AM, Matthews DB, Best PJ. Ethanol, memory, and hippocampal function: a review of recent findings. Hippocampus 2000; 10: 88-93. https://doi.org/10.1002/ (SICI)1098-1063(2000)10:1<88::AIDHIPO10>3.0.CO;2-L

Wojsiat J, Zoltowska KM, Laskowska-Kaszub K, Wojda U. Oxidant/antioxidant imbalance in Alzheimer's disease: therapeutic and diagnostic prospects. Oxid Med Cell Longev 2018; 2018. https://doi.org/10.1155/2018/64358 61

Zhao J, Bi W, Xiao S, Lan X, Cheng X, Zhang J, et al. Neuroinflammation induced by lipopolysaccharide causes cognitive impairment in mice. Sci Rep 2019; 9: 1-12. https://doi.org/10.1038/s41598-019-42286-8 